See Article page 480.

\section{Commentary: Aortic valve endocarditis: Flexibility is the operative principle in the art of war}

\author{
Heidi B. Nafday, MD, and Eugene A. Grossi, MD \\ Don't flail against the world, use it. Flexibility is the \\ operative principle in the art of war
}

-Sun Tzu

Aortic valve endocarditis continues to remain a serious problem that puts patients at high risk for perioperative morbidity and mortality. Irrespective of advances in transcatheter techniques, active endocarditis remains a problem that must be addressed with open surgical debridement for control of infection. As a greater volume of routine aortic valve replacements is managed with a less-invasive approach, the complexity of an "average" aortic valve replacement may also be expected to increase. Understanding of aortic root anatomy and approaches to repair will become increasingly important to provide patients the best-possible outcomes.

In their thoughtful review, Clemence and colleagues ${ }^{1}$ looked at 299 patients with aortic valve endocarditis. They compared 97 patients who had stented valves with 168 patients with stentless valves. They concluded that results were comparable, with a 30-day mortality of $4.1 \%$ and $6.0 \%$ and 5 -year survival of $52 \%$ and $63 \%$ and reoperation rates of $12 \%$ and $3.4 \%$, respectively. These outcomes highlight the high morbidity associated with aortic valve endocarditis. Several previous studies have sought to clarify which conduit-homograft, porcine stentless, stented, or mechanical—would have the best long-term durability and freedom from reinfection. ${ }^{2-4}$

From the Department of Cardiothoracic Surgery, NYU Langone Health, New York, NY.

Disclosures: The authors reported no conflicts of interest.

The Journal policy requires editors and reviewers to disclose conflicts of interest and to decline handling or reviewing manuscripts for which they may have a conflict of interest. The editors and reviewers of this article have no conflicts of interest.

Received for publication Sept 5, 2020; revisions received Sept 5, 2020; accepted for publication Sept 8, 2020; available ahead of print Sept 12, 2020

Address for reprints: Eugene A. Grossi, MD, Department of Cardiothoracic Surgery, NYU Langone Health, 530 First Ave, Suite 9V, New York, NY 10016 (E-mail:

Eugene.Grossi@nyulangone.org).

J Thorac Cardiovasc Surg 2022;164:488

$0022-5223 / \$ 36.00$

Copyright (c) 2020 by The American Association for Thoracic Surgery

https://doi.org/10.1016/j.jtcvs.2020.09.029

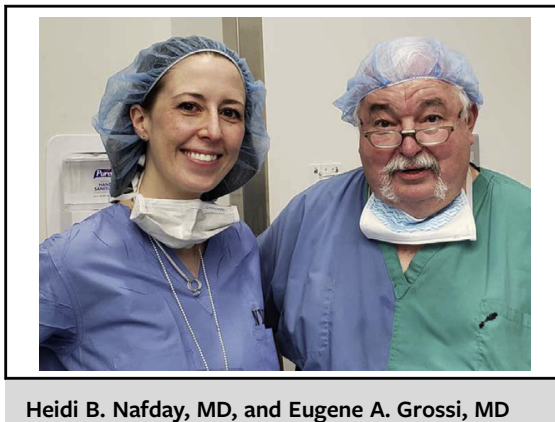

Heidi B. Nafday, MD, and Eugene A. Grossi, MD

CENTRAL MESSAGE

Different operative strategies for aortic endocarditis yield similar outcomes. An individual's pathology should dictate the most appropriate surgical strategy.

This study highlights the importance of flexibility in approaching complex surgical problems. On one hand, a surgeon may have the best results with a particular valve with which they are the most experienced and comfortable-this study allows that flexibility to routinely use either stented or stentless in aortic valve endocarditis. However, despite advances in cardiac imaging, the extent of valvular infection and potential abscess may not be fully appreciated until visualized in the operating room. As the authors highlight, a key step in surgical management is complete tissue debridement to minimize risk of reinfection. Thus, one might find themselves with a more complex root defect to repair than initially expected during preoperative evaluation, which might change the selection of conduit. Knowing that a stented or stentless valve would provide similar outcomes allows us to proceed by focusing on the best repair for an individual patient.

\section{References}

1. Clemence J, Caceres J, Ren T, Wu X, Kim KM, Patel HJ, et al. Treatment of aortic valve endocarditis with stented or stentless valve. J Thorac Cardiovasc Surg. 2022;164:480-7.e1

2. Yanagawa B, Mazine A, Tam DY, Jüni P, Bhatt DL, Spindel S, et al. Homograft versus conventional prosthesis for surgical management of aortic valve infective endocarditis: a systematic review and meta-analysis. Innovations. 2018;13: 163-70.

3. Kytö V, Ahtela E, Sipilä J, Rautava P, Gunn J. Mechanical versus biological valve prosthesis for surgical aortic valve replacement in patients with infective endocarditis. Interact Cardiovasc Thorac Surg. 2019;29:386-92.

4. Savage EB, Saha-Chaudhuri P, Asher CR, Brennan JM, Gammie JS. Outcomes and prosthesis choice for active aortic valve infective endocarditis: analysis of the Society of Thoracic Surgeons adult cardiac surgery database. Ann Thorac Surg. 2014;98:806-14. 